\title{
Studies in Jewish Culture and Society
}

A SERIES OF THE

CENTER FOR ADVANCED JUDAIC STUDIES

U N I VERSITY OF P E N S Y LVA N I A 